\title{
Assessment of Critical Fire Risks in an Industrial Estate Using a Combination of Fuzzy Logic, Expert Elicitation, Bow-tie, and Monte Carlo Methods
}

\section{Gholamreza Nabi Bidhendi', Hajar Mohammadzadeh Bahar,"*}

${ }^{1}$ Professor of Environmental Engineering, Faculty of Environment, University of Tehran, Tehran, Iran

${ }^{2}$ PhD Student, Head of the Environment Industrial Estate of Tehran, Tehran, Iran

* Corresponding Author: Hajar Mohammadzadeh Bahar, Head of the Environment Industrial Estate of Tehran, Tehran, Iran. Email: hmbahar@yahoo.com

\begin{tabular}{|c|c|}
\hline & Abstract \\
\hline $\begin{array}{l}\text { Received: } 12 / 02 / 2019 \\
\text { Accepted: } 13 / 03 / 2019\end{array}$ & $\begin{array}{l}\text { Background and Objective: Industrial estates have been described as } \\
\text { highly prone to fire incidents. According to the baseline studies, more than } \\
85 \% \text { of the industrial accidents occurring in industrial estates during the } 80 \mathrm{~s}\end{array}$ \\
\hline $\begin{array}{l}\text { How to Cite this Article: } \\
\text { Nabi Bidhendi Gh, Mohammad- } \\
\text { zadeh Bahar H. Assessment of } \\
\text { Critical Fire Risks in an } \\
\text { Industrial Estate Using a } \\
\text { Combination of Fuzzy Logic, } \\
\text { Expert Elicitation, Bow-tie, and } \\
\text { Monte Carlo Methods. J Occup } \\
\text { Hyg Eng. 2019; 5(4): 57-65. } \\
\text { DOI: 10.29252/johe.5.4.57 }\end{array}$ & $\begin{array}{l}\text { and } 90 \text { s were fire incidents affecting more than one factory in } 10 \% \text { of the } \\
\text { cases. } \\
\text { Materials and Methods: After the identification of } 30 \text { high-risk industries } \\
\text { in Abbasabad industrial estate, a fault tree was designed using the hazard } \\
\text { and operability analysis (HAZOP). In the next stage, the weak links in the } \\
\text { system were pinpointed using quantitative and qualitative analysis and } \\
\text { Bayesian network. The failure rate of each area was predicted using the } \\
\text { available data and experts' opinions, and then calculated using the fuzzy } \\
\text { logic and Monte Carlo methods. The data were analyzed in the Crystalball } \\
\text { software. After the analysis of the risks, the critical risks were identified and } \\
\text { filtered using the Bowtie method, and then subjected to the management } \\
\text { process. } \\
\text { Results: The consultation with industrial experts during the HAZOP process } \\
\text { and application of filtration resulted in the identification of } 15 \text { major } \\
\text { incidents, } 9 \text { and } 6 \text { events of which were probabilistic and fuzzy, respectively. } \\
\text { The risks were rated based on the experts'opinions and the given model; in } \\
\text { this regard, the foam and paint industries gained the highest modeling score. } \\
\text { Conclusion: The sensitivity analysis of failure probability revealed that the } \\
\text { industries using or producing materials with a low flammable point have a } \\
\text { higher risk; therefore, more attention should be paid to these industries to } \\
\text { prevent the fire incidents. The application of the results of this study in the } \\
\text { development of the required guidelines and trainings for the industrial } \\
\text { managers resulted in a decrease in the number of accidents in Abbasabad } \\
\text { estate. }\end{array}$ \\
\hline
\end{tabular}

Keywords: Crisis Management; Bow-tie Evaluation Model; Fuzzy Logic 
dof: $10.29252 /$ johe. 5.4 .57

\section{آناليز ريسكهاى بحر انى ناشى از حريق يك شهر ك صنعتى با تلفيقى از روشهاى منطق فازى، نظرات خبر تان، Bow-tie و

\author{
غلامرضا نبى بيدهندى'؛ هاجر محمدزاده بهار ז.*
}

' استاد كروه مهندسى محيط زيست، دانشكده محيط زيست دانشكاه تهران، تهران، ايران

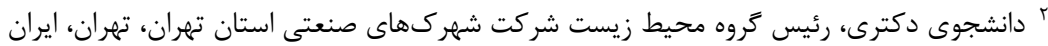
* نويسنده مسئول: هاجر محمدزاده بهار، رئيس كروه محيط زيست شركت شهر كهاى صنعتى استان تهران، تهران، ايران. ايميل: hmbahar@yahoo.com

جكيده

سابقه و هدف: شهركهاى صنعتى داراى يتانسيل بالايى در رخدادهاى آتشسوزى هستند. مطابق با

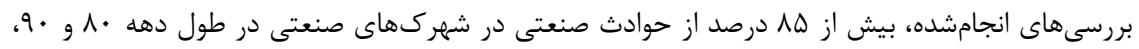

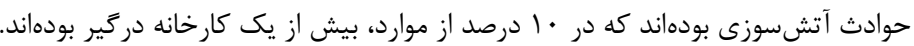

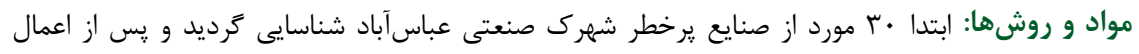
Bayesian (Hazard and Operability Analysis) HAZOP و آناليزهاى كمى و كيفى، لينكهاى ضعيف سيستم مشخص شدند و نرخ شكست در هر نقطه با استفاده از

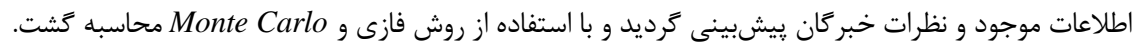

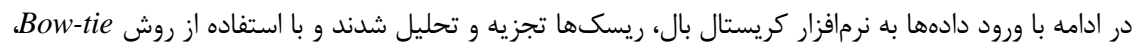

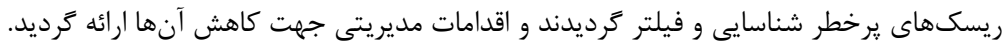

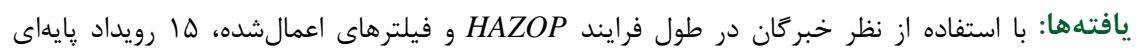

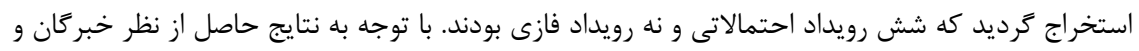

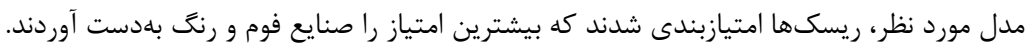

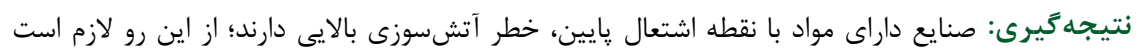

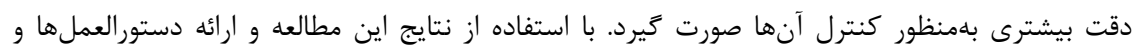

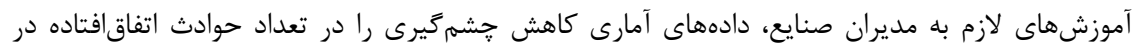
شهرك صنعتى عباس آباد نشان دادند.

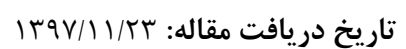
تاريخ هذيرش مقاله:

تمامى حقوق نشر براى دانشكاه علوم يزشكى همدان محفوظ است.

وازَّان كليدى: مدل ارزيابى Bow-tie؛ مديريت بحران؛ منطق فازى

ارتباط تمامى مؤلفهها در تحليل عوامل بالقوه آسيبرسان با

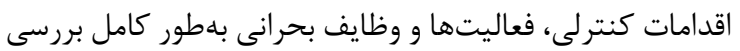
مى

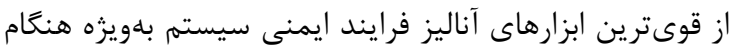

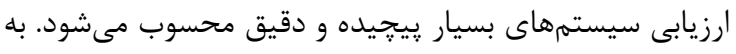

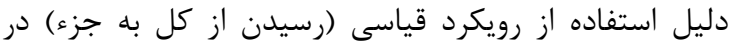
اين روش، بسيارى از تجزيه و تحليل

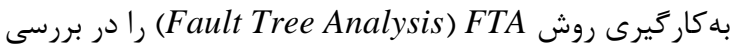

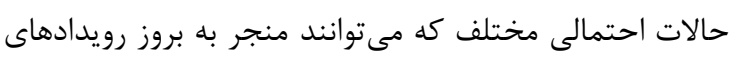
مطلوب يا نامطلوب در سطح سيستم شوند، بسيار مفيد

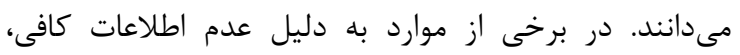

مقلدمه

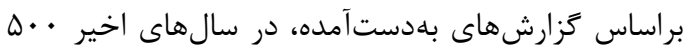
فرم گزارش دهى از حوادث صنعتى در كل كشور كه به تبع آنها

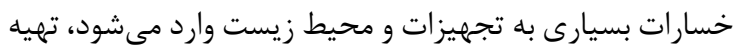

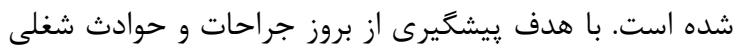

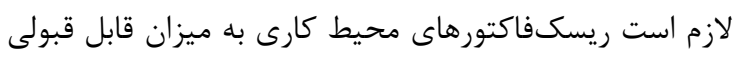

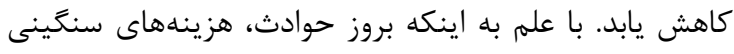

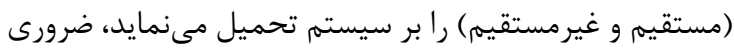

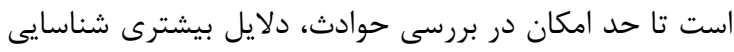

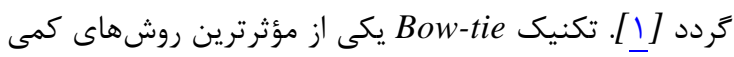

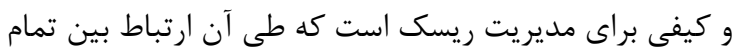
عوامل مرتبط با فرايند خطر نشان داده ريس مىشود. همجنين 
شكست محاسبه گرديد. در مرحله بعد با ورود دادهها به نرمافزار

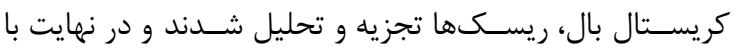

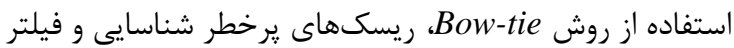

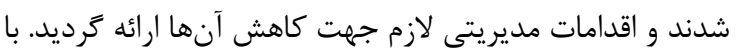

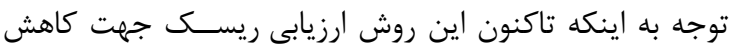

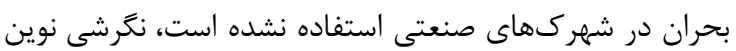
جهت مديريت بحران محسوب مىشود.

\section{تجزيه و تحليل درخت خطا}

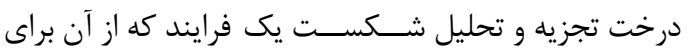

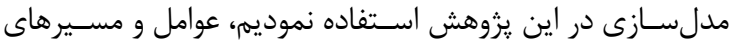

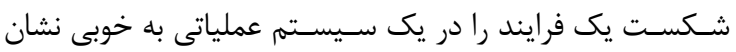
مىدهد. اين رويكرد بر احتمال وقوع رويدادهاى نامطلوب با بيان

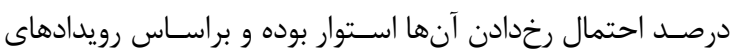

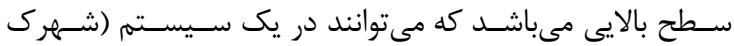
صنعتى) رخ دهند. شايان ذكر است كه تلاش براى رديابى آنها با بالثيا

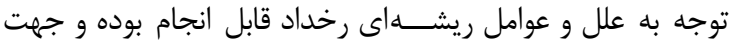

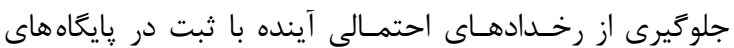

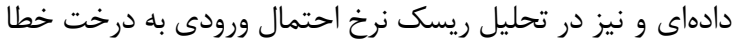

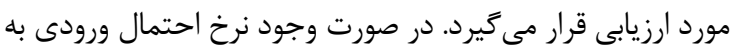

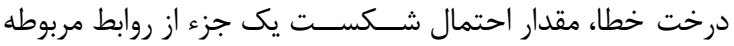

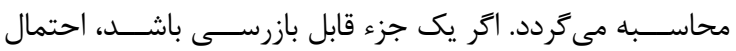

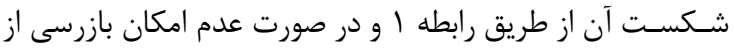

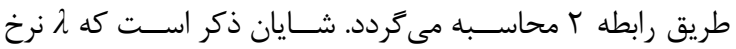

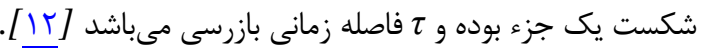
$p(t)=1 / 2 \tau \lambda$ رابطه | $p(b)=1-e^{(\tau \lambda)}$ رابطه r

در تحليـل كمى درخت خطا براى محاســـبه احتمال وقوع

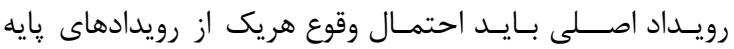
مشــخص گردد؛؛ با مشــخص بودن احتمال وقوع آنها، احتمال

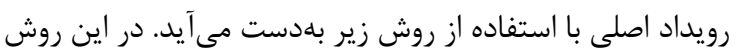

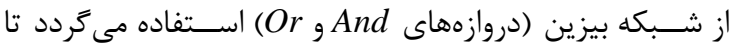

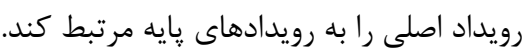

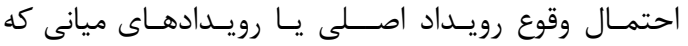

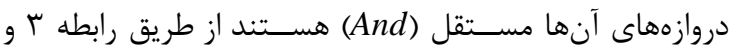

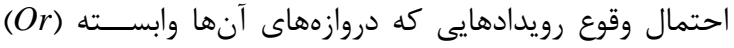

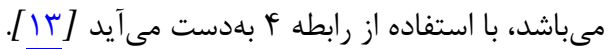

$\mathrm{Q}_{\mathrm{and}}(\mathrm{t})=\prod_{j=1}^{m} q_{j(t)} \quad$ رابطه

$\mathrm{Q}_{\mathrm{or}}(\mathrm{t})=1-\prod_{j=1}^{m}\left(1-q_{j(t)}\right) \quad$ رابطه
دستورالعمل و يا عدم مهارت كافى در ثبت اطلاعات، برآورد دقيق ميزان شكست اجزا كه منجر به وقوع رويداد ناخواسته مىشود، بسيار دشوار است؛ به همين دليل و نيز كسب اطلاعات

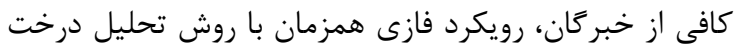

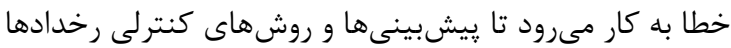

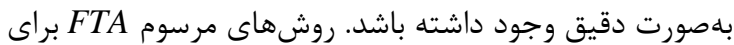
كمى كردن احتمال شكست سيستم، به يك يايكاه داده از صدها

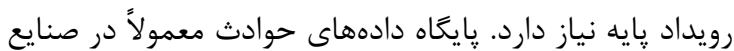

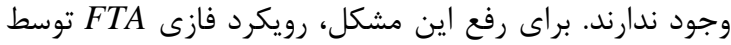
Winkler و Clemen

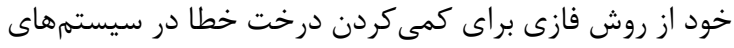

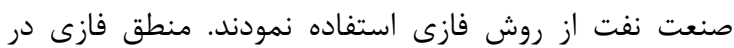
مواجهه و ارزيابى موفقيتهاى نادقيق و مبهمه، امكانى را فراهم

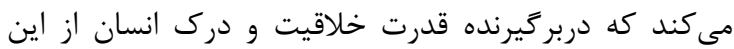

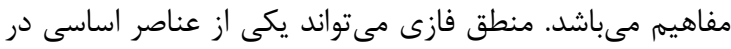

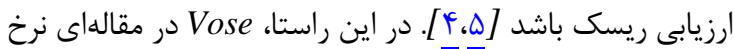

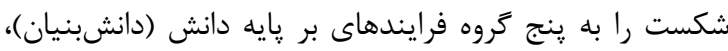

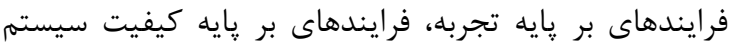

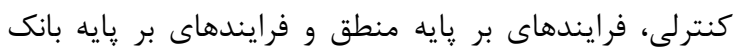

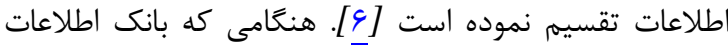
براى رويدادهاى يايهاى وجود نداشته باشد، با استفاده از نظر

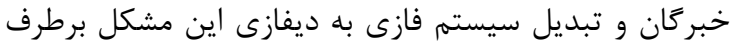

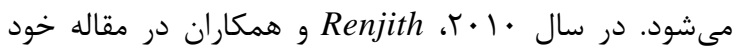

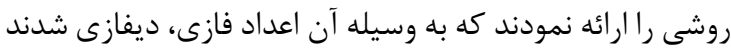

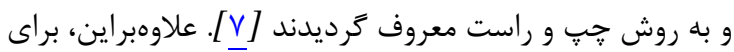

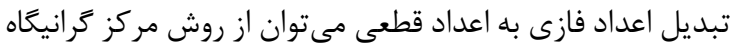

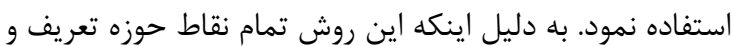

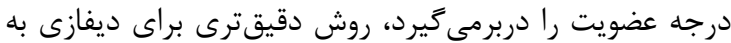

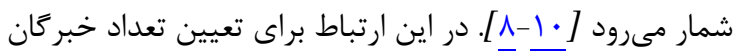

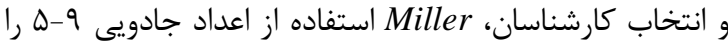

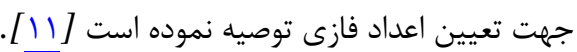

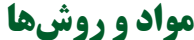

در اين مطالعه با اســـفاده از تلفيقى از روش Bow-tie، منطق فازى، نظرات خبر گان و Monte Carlo اقدام به ارزيابى إنى ريسـكهاى بحرانى ناشـى از حريق در برخى از صـنايع شهرى

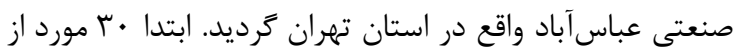

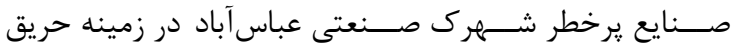

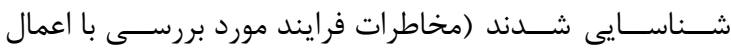
HAZOP تهيه شدند و درخت خطاى مربوطه رسم ترديد) و در

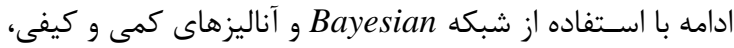
لينكهاى ضعيف سيستم مشخص شدند و نرخ شكست در هر

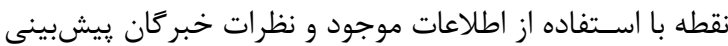
كرديد. در ادامه با استفاده از روش فازى و Monte Carlo 
خبر Fان صـنعتى به مقادير احتمالى مورد ارزيابى تبديل مى كند

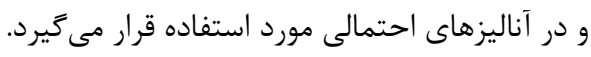

\section{مرحله ا. انتخاب خبركان}

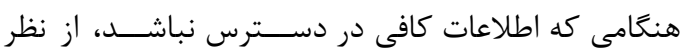

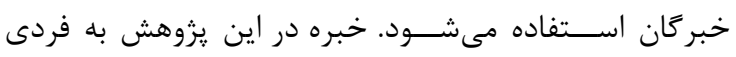

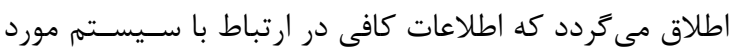

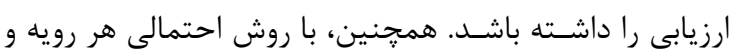

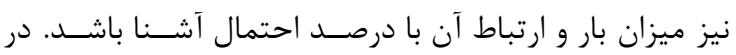

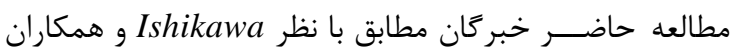

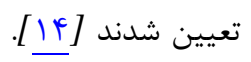

\section{مرحله r. وزندهى خبركان}

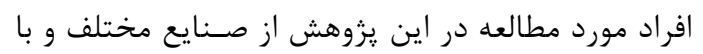

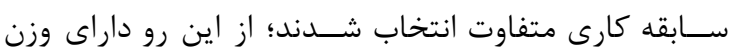

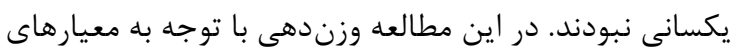

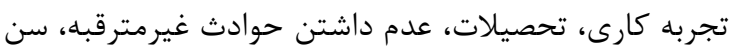

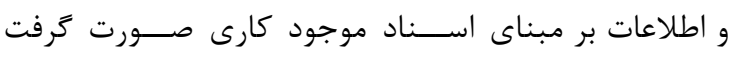

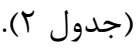

در اين رابطهها m= تعداد كل رويدادهاى ورودى به دروازه

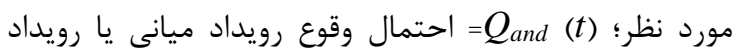

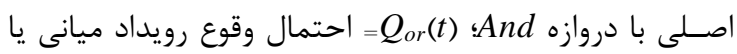

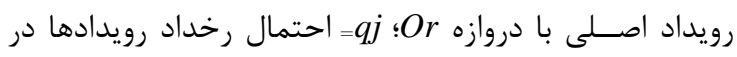

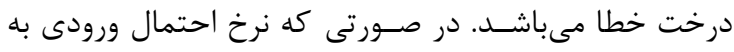

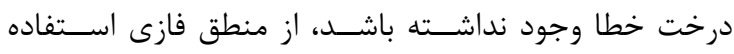

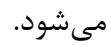

$$
\text { درخت خطاى فازى }
$$

معـايـب درخت خطا وقتى اســت كه دادههاى موهومى فيى

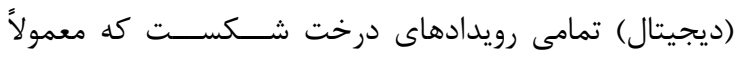

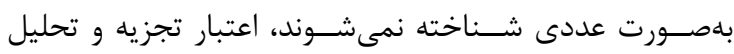

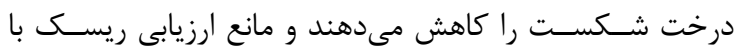

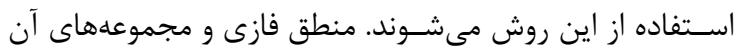

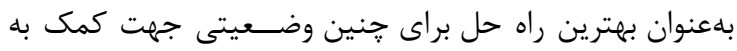
تجزيه و تحليل شـكست ظاهر مى شــوند. هنكامى كه اطلاعات

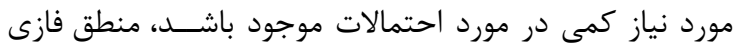

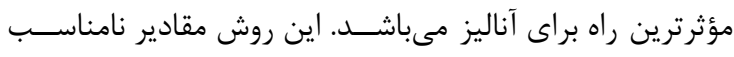

\begin{tabular}{|c|c|c|c|}
\hline امتياز & طبقدبندى & وضعيت & رديف \\
\hline f & مهندس & عنوان & \\
\hline r & بازرس كنترل كننده & & 1 \\
\hline r & سريرست كارگر تكنسين & & \\
\hline 1 & كارَر ساده & & \\
\hline f & r. & تجربه & \\
\hline r & $r \cdot-r \cdot$ & & $r$ \\
\hline r & $1 \cdot-r \cdot$ & & 1 \\
\hline 1 & $1-1$ & & \\
\hline r & دكترى & تحصيلات & \\
\hline r & مهندس و كارشناسى ارشد & & س \\
\hline$r$ & فوق دييلم و ديِلم & & \\
\hline 1 & دييلم و زير دييلم & & \\
\hline r & $>\Delta$ & سن & \\
\hline r & $\varphi \cdot-\Delta$. & & 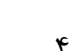 \\
\hline r & $r \cdot-r^{c} \cdot$ & & 1 \\
\hline 1 & $<r$. & & \\
\hline
\end{tabular}

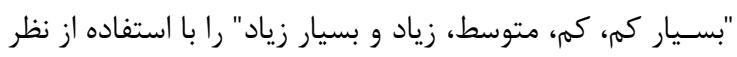

\begin{tabular}{|c|c|c|c|c|}
\hline \multicolumn{4}{|c|}{ وز وزن وازههاى محاورهاى } & \multirow{2}{*}{ بسيار كمازههاى محاورهاى } \\
\hline$\cdot / 4$ & $\cdot / 1$ & $\cdot$ & · & \\
\hline$\cdot / 4$ & $\cdot / r \Delta$ & $\cdot / r \Delta$ & $\cdot 11$ & كم \\
\hline$\cdot / V$ & $\cdot 10$ & $\cdot / r$ & $\cdot / r$ & متوسط \\
\hline$\cdot 19$ & $\cdot / V \Delta$ & $\cdot / V \Delta$ & .19 & زياد \\
\hline 1 & 1 & $\cdot / 9$ & $\cdot / 1$ & بسيار زياد \\
\hline
\end{tabular}


ذوزنقهاى (رابطه V) نظرات خبركان بلصورت ديفازى تبديل كرديد.

$X^{*}=\frac{\int_{a_{1}}^{a_{2} x-a} \frac{x-a}{a_{2}-a_{1}} x d x+\int_{a_{2}}^{a_{3}} \frac{a_{3}-x}{a_{3}-a_{2}} x d x}{\int_{a_{1} \frac{x-a_{1}}{a_{2}-a_{1}}}^{a_{1}} d x+\int_{a_{2}}^{a_{3}} \frac{a_{3}-x}{a_{3}-a_{2}} d x}=\frac{1}{3}\left(a_{1}+a_{2}+a_{3}\right)$ ابطة

$X^{*}=\frac{\int_{a_{1}}^{a_{2} x-a} \frac{x-a_{1}}{a_{2}-a_{1}} x d x+\int_{a_{2}}^{a_{3}} x d x+\int_{a_{3}}^{a_{4}} \frac{a_{4}-x}{a_{4}-a_{3}} x d x}{\int_{a_{1}}^{a_{2} \frac{x-a_{1}}{a_{2}-a_{1}}} d x+\int_{a_{2}}^{a_{3}} x d x+\int_{a_{3}}^{a_{4}} \frac{a_{4}-x}{a_{4}-a_{3}} d x}=$

$\frac{1}{3} \frac{\left(a_{4}+a_{3}\right)^{2}-a_{4} a_{3}-\left(a_{1}+a_{2}\right)^{2}+a_{1} a_{2}}{\left(a_{4}+a_{3}-a_{2}-a_{1}\right)}$

رابطه

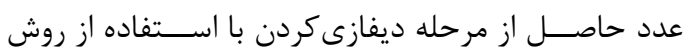

Onisawa

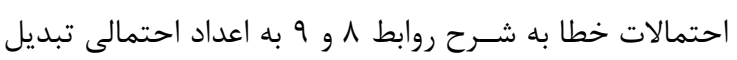

$$
\text { كرديد [IV،IN] }
$$

$\mathrm{FFP}=\left\{\begin{array}{cc}\frac{1}{1 \cdot{ }^{k}} & \text { FPS } \neq 0 \\ 0 & \text { FPS }=0\end{array}\right.$

رابطه

$\mathrm{k}=\left[\frac{1-\mathrm{FPS}}{\mathrm{FPS}}\right]^{\frac{1}{r}} \times r / r \cdot 1$

رابطه 9
مرحله "r.كمىسازى نظر خبركان

براى كمىســازى نظر خبركان در مورد ميزان رخدادئس ادهاى

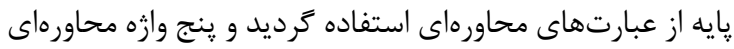

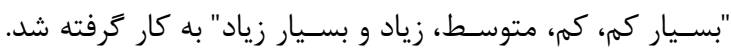

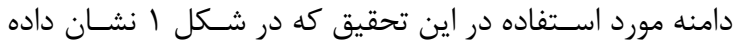

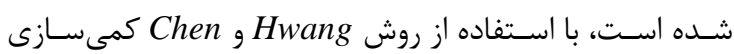
كرديد [هإ]

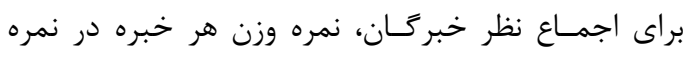

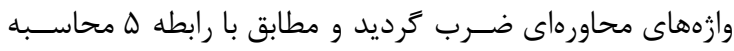

$M=\sum_{j}^{i} W_{i} A_{j} \quad i=1,2,3,4 \quad \Delta$ رابطه

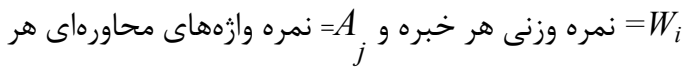
خبره مىباشد. با توجه به تجربيات كسـب شده از نظرات خبركان، جهت

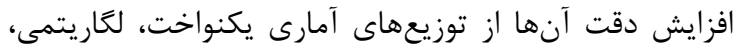

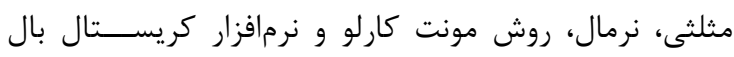

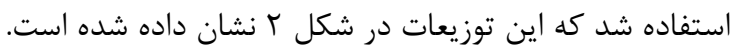

احتمال فازى يا مقدار (Fuzzy Possibility Score) FPS ديفـازى كردن يك رخداد يا واقعه مىباشـــد. يس از اينكه نرخ

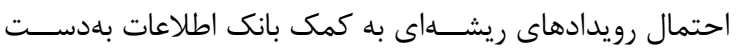

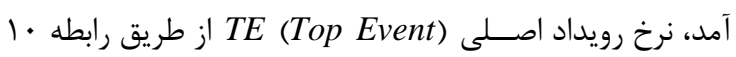
محاسبه مى تردد.

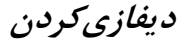
ديفـازىكردن يــ فراينـــ تبـديل مقادير مفهومى به مقادير

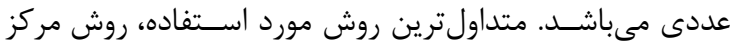

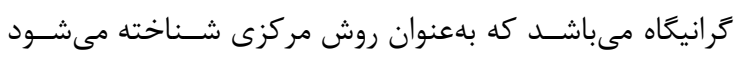

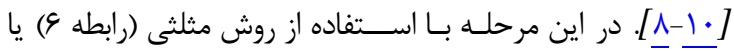
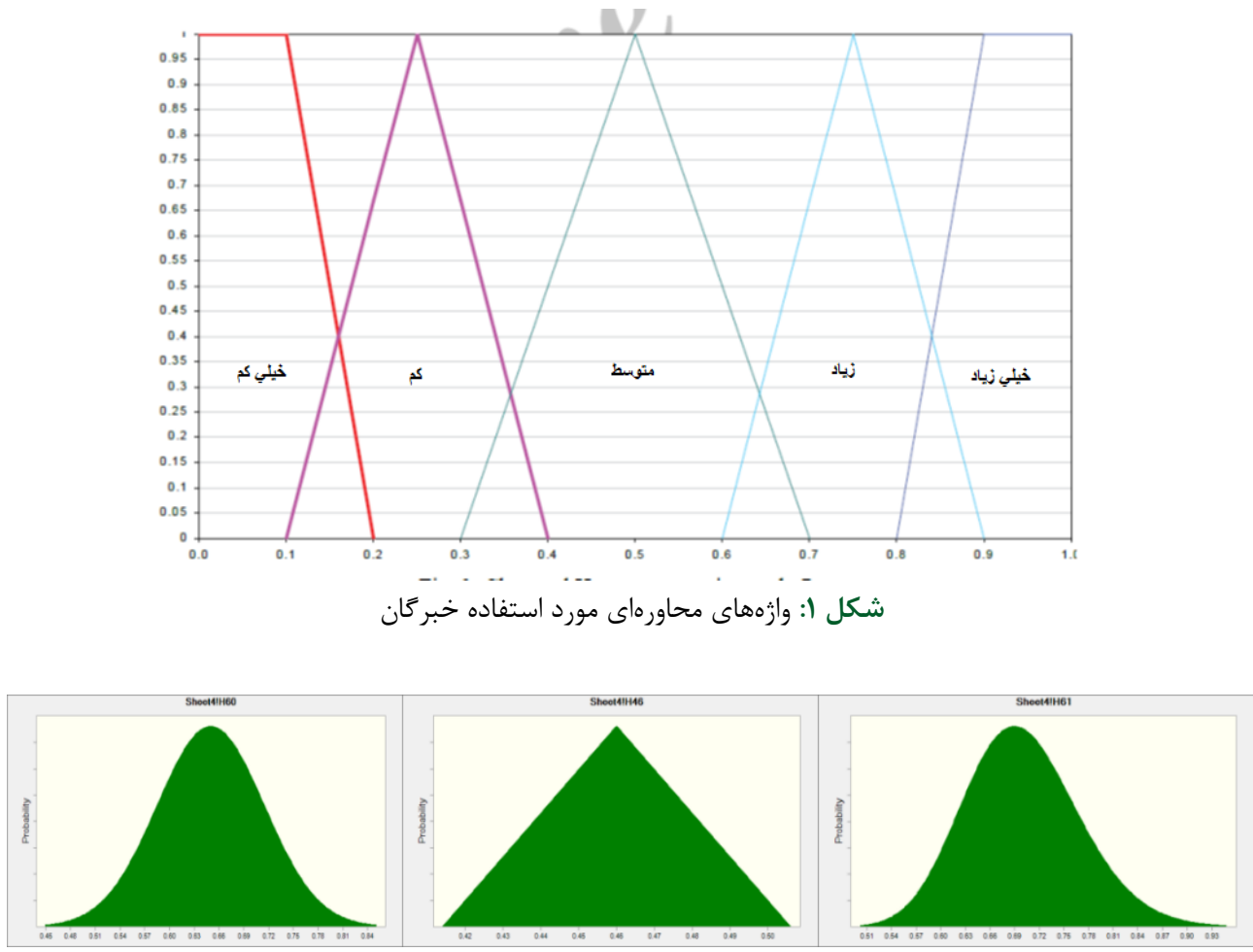

شكل r: توزيعهاى يكنواخت، لكاريتمى، مثلثى و نرمال 
يونوليت، فوم، شــيرآلات، مازول، صــنايع غذايى، رنغســـازى،

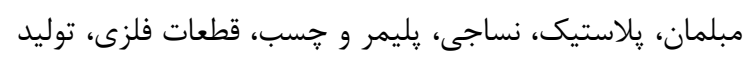

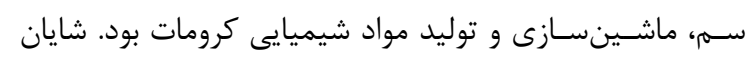

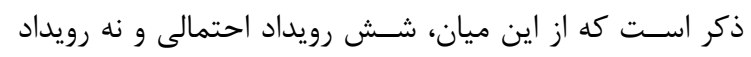

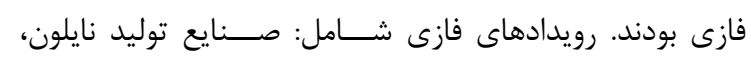

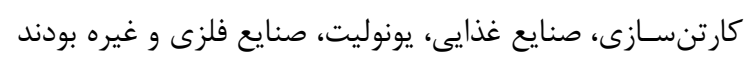

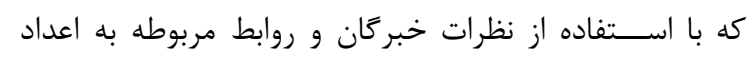

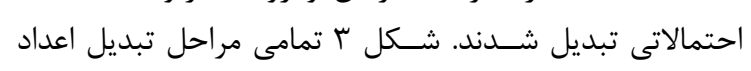

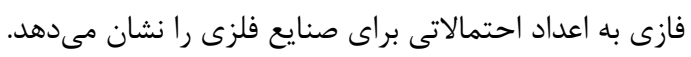

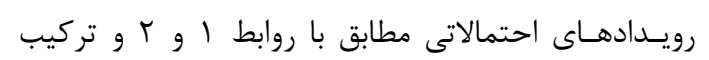

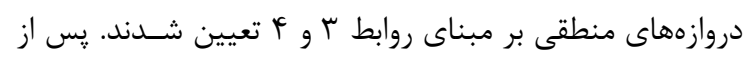

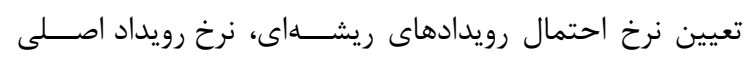

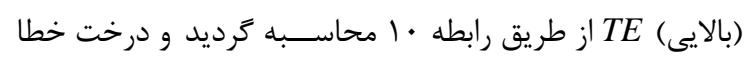

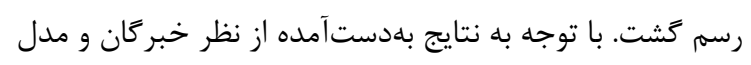

$E=1-\left[\left(1-M C S_{1}\right) \times\left(1-M C S_{2}\right) \times \ldots \times\right.$

$\left.\left(1-M C S_{N}\right)\right]$

ارزيـابى دقيق احتمـال رخــداد يك واقعه يا بحرانى ترين

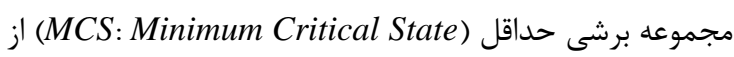
طريق رابطه || (رابطه فاسل- وسلى) محاسبه كرديد.

$F V_{i}=\frac{M C S_{i}}{T E}$

رابطه 11

\section{يافتهها}

در اين مطالعه ·ـ مورد از مهمترين آتشسوزىهاى رخداده

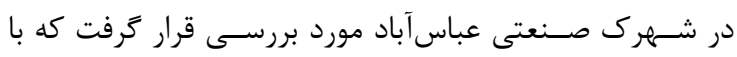

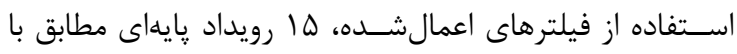

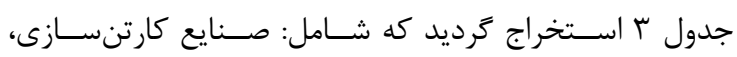

جدول ب: ليست مهممترين صنايع يرخطر شهرك

\begin{tabular}{|c|c|c|c|}
\hline احتمال نرخ شكست رويداد محاسبهشده از نظر & نوع فعاليت & 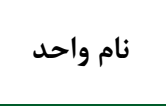 & رديف \\
\hline$\cdot / \cdot$ fFfl. $F$ & 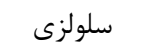 & 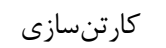 & 1 \\
\hline$\cdot / \cdot+\cdot \cdot 9 \Lambda r \Lambda$ & 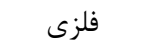 & قطعات فلزى & r \\
\hline . . . rIfar & 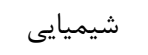 & رنغَسازى & r \\
\hline$\cdot|\cdot r| r \cdot \varepsilon \Delta$ & سلولزى & كاغذسازى & f \\
\hline • $/ \cdot \cdot q \wedge r$ & 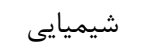 & نايلون & $\Delta$ \\
\hline$\cdot / \cdot r q 4 \mid \Delta \Lambda$ & 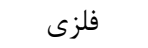 & 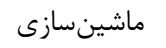 & द \\
\hline 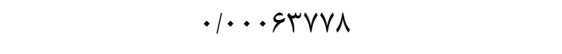 & 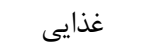 & غذايى & $\checkmark$ \\
\hline$\cdot \cdot \cdot r \wedge \Delta \mid Y S$ & 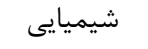 & توليد سم & $\wedge$ \\
\hline . . . r\&TVGq & شيميايى & يونوليت & 9 \\
\hline$\cdot 1 \cdot r 1919$ & 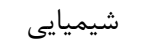 & 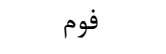 & $1 \cdot$ \\
\hline$\cdot 1 \cdot .194 \cdot r t$ & 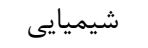 & يليمر و جسب & 11 \\
\hline 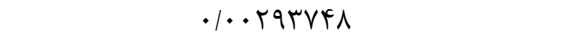 & 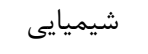 & 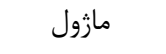 & ir \\
\hline.$/ \cdot 19 T \Delta$ & 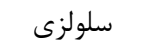 & 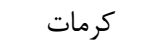 & Ir \\
\hline$\cdot 1 \cdot \cdot 10$ & 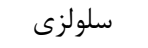 & 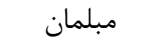 & if \\
\hline . & فلزى & شيرآلات & 10 \\
\hline
\end{tabular}

\begin{tabular}{|c|c|c|c|c|c|c|c|c|c|c|c|}
\hline V & its & $-n$ & $-\infty \Delta$ & $-\infty$ & $=$ & - سموات & $=x-2$ & 促 & وتم حريجرة & & $-\infty$ \\
\hline$T=(E 2)$ & $-i \pi$ & $-\infty$ & $-r \neq \Delta$ & $-\infty$ & ? & لمت ناظمر & $b=2$ & $191-$ & $T \rightarrow \Delta+\Delta-1 T$ & $-i T R T+\Delta T A F$ & $-\pi x+F$ \\
\hline$T=$ (E3) & $\infty$ & $-\pi$ & $-r T \Delta$ & $-x \neq$ & $\tau$ & هب. & $\mid$ & $r-t a$ & 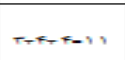 & -TTETSATT & $-i t+t s$ \\
\hline (E 1) & 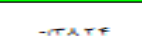 & & & & T & & كتاريشاس & $T-T=$ & TtT+tal & 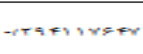 & -itaft \\
\hline 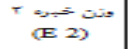 & $-\pi+t s$ & & & & & & & & $r=$ & & \\
\hline 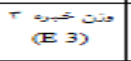 & ataft & & & & & & & & & & \\
\hline 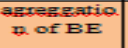 & meteV & 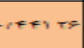 & ferafa & HTART & & & & & & & \\
\hline ديقازى & $1+4 \lambda a-\gamma \infty$ & & & & & & & & & & \\
\hline & $m-1+4-f$ & & & & & & & & & & \\
\hline & TDSTIFIA9F & & & & & & & & & & \\
\hline 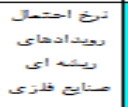 & $-r-\ldots+t a y d e$ & & & & & & & & & & \\
\hline
\end{tabular}

شكل ऍ: مراحل ديفازى كردن صنايع فلزى 
بلوجودآورنده رويداد اصلى همراه با شاخهها و دروازههاى منطقى و

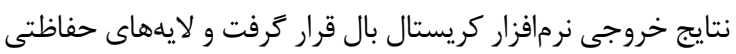

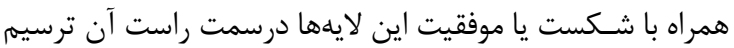

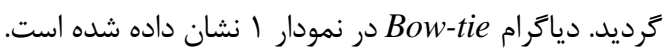

مورد نظر، ريسكها امتيازبندى شدند كه بيشترين امتياز راصنايع توليد فوم و رنگ به خود اختصـاص دادند. در اين مطالعه دياترام Bow-tie با اسـتفاده از دادها و اطلاعات مربوط به درخت خطا و

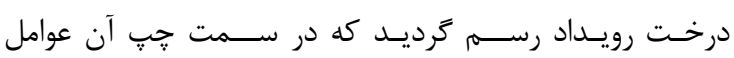

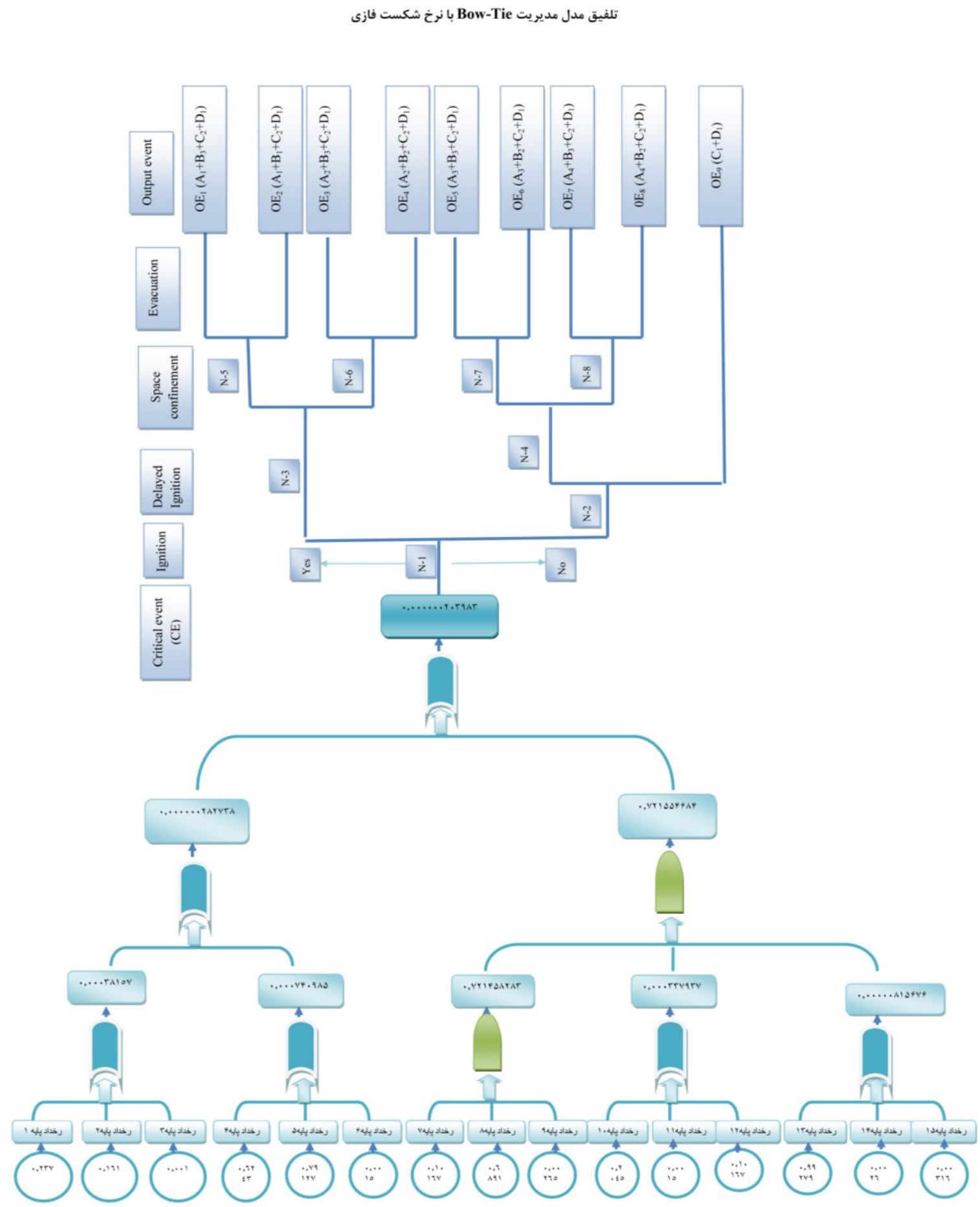

نمودار ا: تلفيق مدل مديريت Bow-Tie با نرخ شكست فازى

و بهعنوان رويداد يايه در درخت خطا رسم گرديدند. لازم به ذكر است در مواردى كه نرخ شكست مشخص نبود، از نظر خبر گان

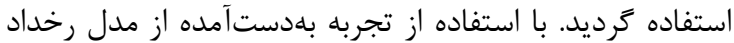

با توجه به نتايج HAZOP در بين •r صنعت مختلف مورد

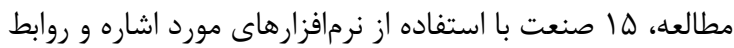

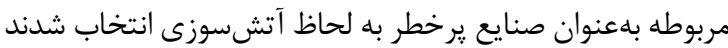


(هكَزامتيلن دىايزوسيانات) و نيز در توليد رنغ مواد شيميايى

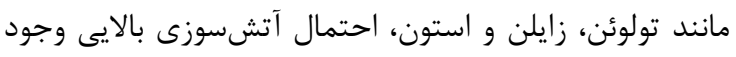
دارد. در اين راستا، دستورالعملهاى مربوطه نظير استفاده از

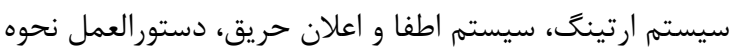

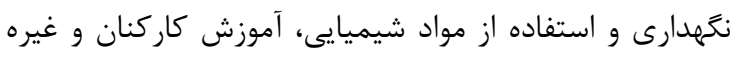
ارائه كرديد.

\section{نتيجه كيرى}

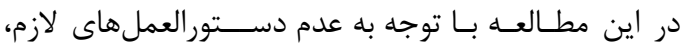

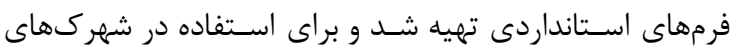

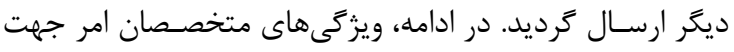

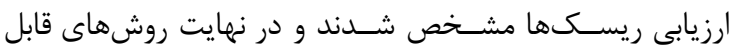

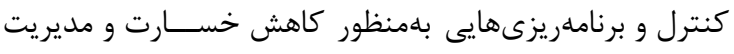

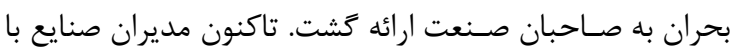

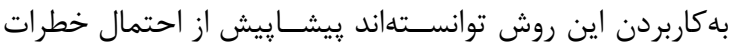

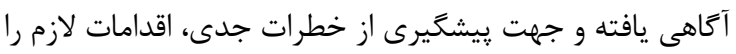

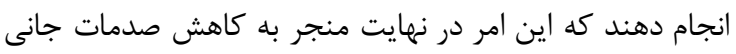

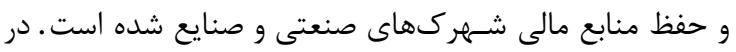

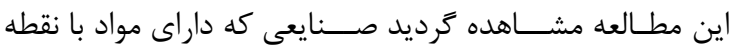

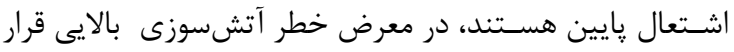

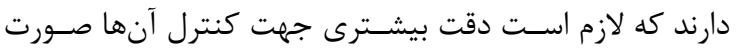

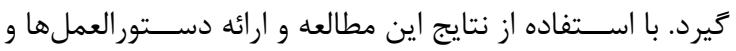

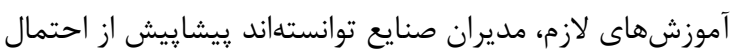

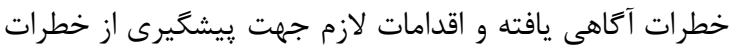

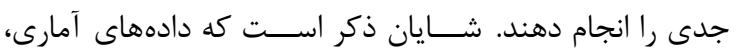

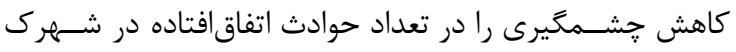
صنعتى عباسآباد نشان دادند.

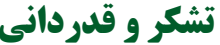

در پايان از كاركنان محترم واحدهاى فنى و محيط زيست شهرك صنعتى عباسآباد به سبب همكارىهاى مفيدى كه بان بان نويسندكان اين مقاله داشتند نهايت تقدير و تشكر راد بادئ هاريم.

\section{REFERENCES}

1. Iran Small Industries and Industrial Parks Organization (ISIPO). Available at: URL: www.Isipo.ir; 2019.

2. Duijm NJ. Safety-barrier diagrams as a safety management tool. Reliabil Eng Syst Saf. 2009;94(2):332-41. DOI: 10.1016/j.ress.2008.03.031

3. Clemen RT, Winkler RL. Combining probability distributions from experts in risk analysis. Risk Anal. 1999;19(2):187-203. DOI: 10.1023/A:1006917509560

4. Zadeh LA. Fuzzy sets. Inform Control. 1965;8(3):338-53. DOI: 10.1016/S0019-9958(65)90241-X

5. Zimmermann HJ. Fuzzy set theory and its applications. $2^{\text {nd }}$ ed. Boston: Kluwer Academic Publisher; 1991. P. 36-43.

6. Vose D. Risk analysis: a quantitative guide. $2^{\text {nd }}$ ed. New Jersey: John Wiley \& Sons; 2000.

7. Renjith VR, Madhu G, Nayagam VL, Bhasi AB. Twodimensional fuzzy fault tree analy-sis for chlorine release from a chlor-alkali industry using expert elicitation. J
شكست فازى، با بهكاربردن توزيعها، نتايج بسيار بهترى از روش Monte Carlo

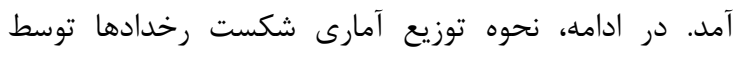

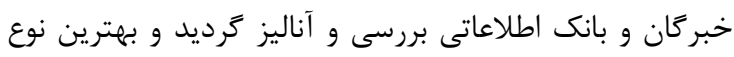

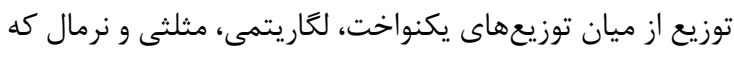

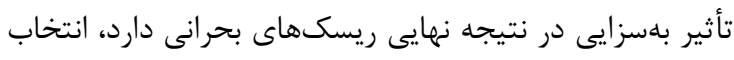

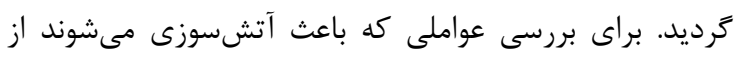

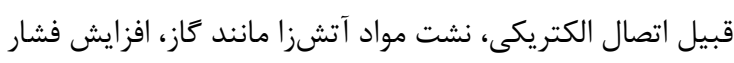

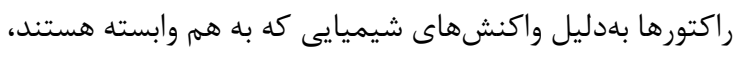

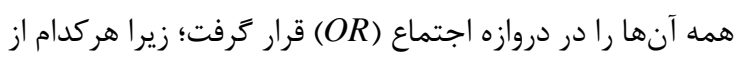
اين اتفاقات منجر به شكست سيستم ايمنى ايجادشده كه همان

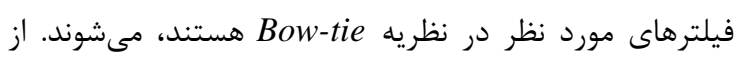

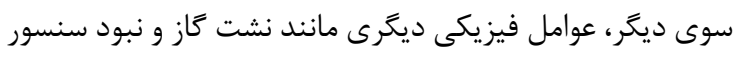

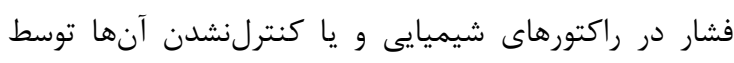

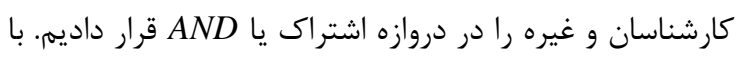

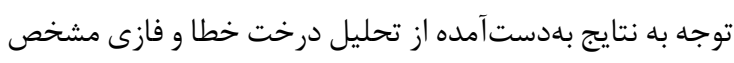

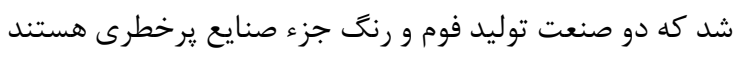

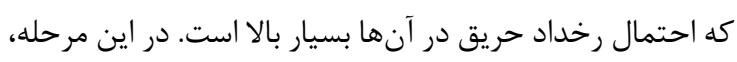

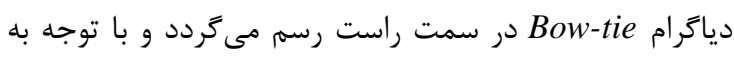

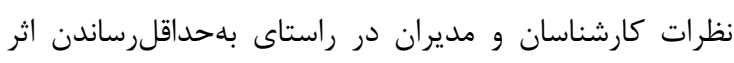

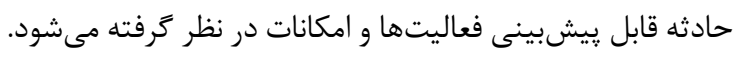

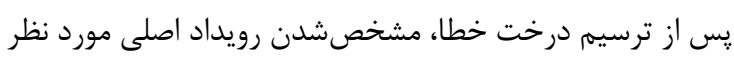

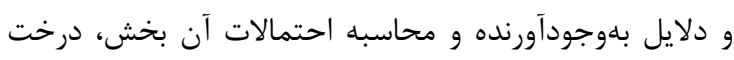

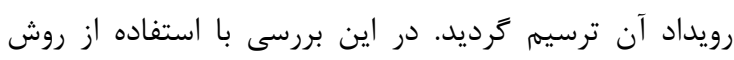

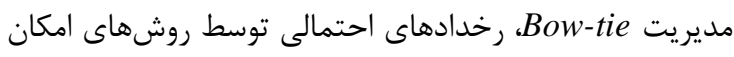

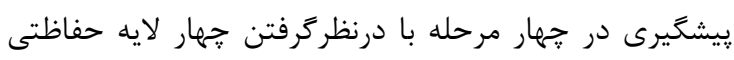

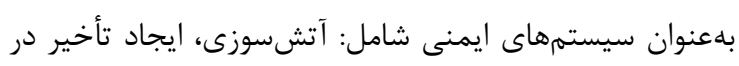

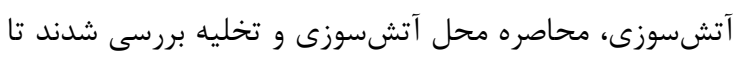

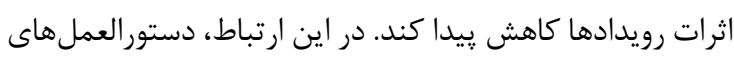

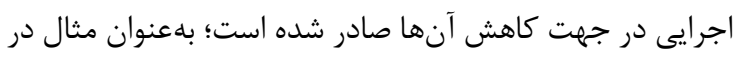

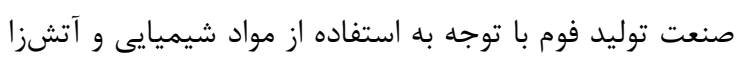
مانند متيلن كلرايد، (Toluene Diisocyanate) TDI (تولوئن (Heexamethylene diisocyanate) HDI مى (توني

Hazard Mater. 2010;183(1):103-10. PMID: 20674168 DOI: 10.1016/j.jhazmat.2010.06.116

8. Onisawa T. An application of fuzzy concepts to modelling of reliability analysis. Fuzzy Sets Syst. 1990;37(3):267-86. DOI: 10.1016/0165-0114(90)90026-3

9. Onisawa T. Subjective analysis of system reliability and its analyzer. Fuzzy Sets Syst. 1996;83(2):249-69. DOI: 10.1016/0165-0114(95)00381-9

10. Zhao R, Govind R. Defuzzification of fuzzy intervals. Fuzzy Sets Syst. 991;43(1):45-55. DOI: 10.1016/0165-0114(91) 90020-Q

11. Miller GA. The magical number seven, plus or minus two: some limits on our capacity for processing information. Psychol Rev. 1956;63(2):81-97. PMID: 13310704

12. Miri Lavasani MR, Wang J, Yang Z, Finlay J. Application of fuzzy fault tree analysis on oil and gas offshore pipelines. Int J Marine Sci Eng. 2011;1(1):29-42. 
13. Vesely DL, Straub KD, Nolan CM, Rolfe RD, Finegold SM, Monson TP. Purified clostridium difficile cytotoxin stimulates guanylate cyclase activity and inhibits adenylate cyclase activity. Infect Immun. 1981;33(1):285-91. PMID: 6114928

14. Ishikawa A, Amagasa M, Shiga T, Tomizawa G, Tatsuta R, Mieno H. The max-min Delphi method and fuzzy Delphi method via fuzzy integration. Fuzzy Sets Syst. 1993; 55(3):241-53. DOI: 10.1016/0165-0114(93)90251-C

15. Chen SJ, Hwang CL, Hwang FP. Fuzzy multiple attribute decision making: methods and applications. $1^{\text {st }}$ ed. New York:
Springer; 1992.

16. Zhang $X$, Liue $P$. Method for aggregating triangular fuzzy intuitionist fuzzy information and its application to decision making. Technol Econ Dev Econ. 2010;16(2):280-90.

17. Onisawa T. An approach to human reliability in manmachine systems using error possibility. Fuzzy Sets Syst. 1988;

27(2):87-103. DOI: 10.1016/0165-0114(88)90140-6

18. Hauge S, Onshus T. Reliability data for safety instrumented systems-PDS data handbook. $1^{\text {st }}$ ed. New York: SINTEF Technology and Society; 2010 